\title{
Risk of second bone sarcoma following childhood cancer: role of radiation therapy treatment
}

\author{
Boris Schwartz • Mohamed Amine Benadjaoud • Enora Cléro • Nadia Haddy • \\ Chiraz El-Fayech · Catherine Guibout • Cécile Teinturier · Odile Oberlin · \\ Cristina Veres • Hélène Pacquement • Martine Munzer • Tan Dat N'Guyen • \\ Pierre-Yves Bondiau • Delphine Berchery • Anne Laprie • Mike Hawkins • \\ David Winter · Dimitri Lefkopoulos · Jean Chavaudra $\cdot$ Carole Rubino $\cdot$ \\ Ibrahima Diallo $\cdot$ Jacques Bénichou $\cdot$ Florent de Vathaire
}

Received: 15 May 2013/Accepted: 23 December 2013/Published online: 14 January 2014

(C) The Author(s) 2014. This article is published with open access at Springerlink.com

\begin{abstract}
Bone sarcoma as a second malignancy is rare but highly fatal. The present knowledge about radiationabsorbed organ dose-response is insufficient to predict the risks induced by radiation therapy techniques. The objective of the present study was to assess the treatmentinduced risk for bone sarcoma following a childhood cancer and particularly the related risk of radiotherapy. Therefore, a retrospective cohort of 4,171 survivors of a solid childhood cancer treated between 1942 and 1986 in France and Britain has been followed prospectively. We collected detailed information on treatments received during childhood cancer. Additionally, an innovative methodology has been developed to evaluate the dose-response relationship between bone sarcoma and radiation dose
\end{abstract}

B. Schwartz $(\bowtie) \cdot$ M. A. Benadjaoud · E. Cléro · N. Haddy ·

C. El-Fayech · C. Guibout · C. Teinturier - O. Oberlin ·

C. Veres - C. Rubino - I. Diallo - F. de Vathaire

Radiation Epidemiology Group, Unit 1018 INSERM,

Institut Gustave Roussy, Rue Camille Desmoulins,

94805 Villejuif, France

e-mail: boris.schwartz@igr.fr

B. Schwartz - M. A. Benadjaoud - E. Cléro · N. Haddy ·

C. El-Fayech · C. Guibout - C. Teinturier · O. Oberlin ·

C. Veres · D. Lefkopoulos · J. Chavaudra - C. Rubino ·

I. Diallo $\cdot$ F. de Vathaire

Institut Gustave Roussy, 94805 Villejuif, France

B. Schwartz - M. A. Benadjaoud · E. Cléro · N. Haddy ·

C. El-Fayech · C. Guibout - C. Teinturier · O. Oberlin ·

C. Veres - C. Rubino - I. Diallo · F. de Vathaire

Université Paris-Sud, 94800 Villejuif, France

H. Pacquement

Institut Curie, Paris, 75005 Paris, France

M. Munzer · T. D. N'Guyen

Institut Jean Godinot, 51092 Reims, France throughout this cohort. The median follow-up was 26 years, and 39 patients had developed bone sarcoma. It was found that the overall incidence was 45 -fold higher [standardized incidence ratio 44.8, $95 \%$ confidence interval (CI) 31.0-59.8] than expected from the general population, and the absolute excess risk was 35.1 per 100,000 person-years (95\% CI 24.0-47.1). The risk of bone sarcoma increased slowly up to a cumulative radiation organ absorbed dose of 15 Gy [hazard ratio (HR) $=8.2,95 \%$ CI 1.6-42.9] and then strongly increased for higher radiation doses (HR for 30 Gy or more 117.9, 95 \% CI 36.5-380.6), compared with patients not treated with radiotherapy. A linear model with an excess relative risk per Gy of 1.77 (95\% CI 0.6213-5.935) provided a close fit to the data.

\section{P.-Y. Bondiau}

Centre Antoine Lacassagne, 06100 Nice, France

D. Berchery · A. Laprie

Centre Claudius Régaud, 31300 Toulouse, France

M. Hawkins · D. Winter

Department of Public Health and Epidemiology, Centre for

Childhood Cancer Survivor Studies, University of Birmingham,

Birmingham, UK

J. Bénichou

INSERM, U657, 76031 Rouen, France

J. Bénichou

Unité de Biostatistique, Centre Hospitalier Universitaire (CHU)

de Rouen, 76031 Rouen, France

J. Bénichou

Université de Rouen, 76031 Rouen, France 
These findings have important therapeutic implications: Lowering the radiation dose to the bones should reduce the incidence of secondary bone sarcomas. Other therapeutic solutions should be preferred to radiotherapy in bone sarcoma-sensitive areas.

Keywords Bone sarcoma - Childhood cancer . Iatrogenous effects $\cdot$ Radiation therapy $\cdot$ Secondary tumor

\section{Introduction}

Excess of incidence and mortality from a second malignant neoplasm (SMN) is an increasing concern among survivors of childhood cancers (Reulen et al. 2011; Olsen et al. 2009; Friedman et al. 2010; Bassal et al. 2006). Despite their rarity, sarcomas accounted for $19 \%$ of the SMN among survivors aged less than 15 years, $10 \%$ among those aged 15-39 years, 5\% among those aged 40-59 years and almost $0 \%$ for older ages (Olsen et al. 2009). Moreover, bone sarcoma exhibits the highest overall standardized incidence ratio (SIR) for any SMN category (Reulen et al. 2011). However, although radiation dose has been demonstrated to be a major risk factor, the role of radiation dose in the risk of secondary bone sarcoma among survivors of childhood cancers is currently unclear. Indeed, case-control studies investigating the relation between the radiation dose at a particular bone site and the risk of developing bone sarcoma at this site have reached widely different conclusions (Berrington de Gonzalez et al. 2012; Henderson et al. 2012; Kleinerman et al. 2005; Le Vu et al. 1998; Hawkins et al. 1996; Wong et al. 1997; Tucker et al. 1987). This may be due to insufficient follow-up or because of the design of the case-control studies in which evaluation of the dose-response relationship requires the use of the "local dose" of radiation at the sarcoma site of the case and at the same site for its matched controls. When nested in a cohort, practical constraints related to control selection may induce reduction in the case-control study sample and therefore cause some biases.

The highlights of the current study, in addition to being based on a valuable dataset with a long follow-up, are that detailed information on radiotherapy was available and estimates of radiation dose at many sites in each bone were performed for each subject; thus, one could explore the dose-response relationship in a cohort study design instead of through the usual case-control analysis design, taking full advantage of the available data.

The purposes of this cohort study were (1) to investigate the role of the radiation dose in the risk of secondary bone sarcoma in survivors of childhood cancer; (2) to identify primary neoplasm types that contribute most to the risk of secondary bone sarcoma; and (3) to develop an innovative approach that allows modeling of the dose-response relationship in a cohort study design.

\section{Materials and methods}

Patients

\section{Cohort}

A cohort of 4,171 children treated in France and Britain was constituted between 1985 and 1995, comprising patients who were alive without secondary bone sarcoma 5 years after a first solid cancer diagnosis made before the year 1986 and before the ages of 16 years for French patients and 15 years for English patients, who were followed up thereafter. One hundred and forty-three patients who had an osteosarcoma as the first cancer were excluded because, in the case that they developed bone sarcoma during follow-up, it would be impossible to determine whether the bone sarcoma was a second cancer or a recurrence of the first lesion. However, patients treated for Ewing's sarcoma in their childhood were not excluded because if they developed bone sarcoma as second cancer, one would be able to determine whether it was a recurrence or a new cancer, based on histology.

Follow-up for the occurrence of death or second cancer of the 2,967 French patients from the diagnosis of childhood cancer relied exclusively on medical records from the treatment centers and general practitioners and a selfcompleted questionnaire. Cancers declared from the questionnaire were required to be validated by contacting the general practitioner or checking medical records; otherwise, they were not taken into account in analyses. This questionnaire was based on that used in the British Childhood Cancer Survivor Study (Hawkins et al. 2008). A total of 1,825 patients returned the completed questionnaire (sent to 2,449 alive patients) by December 31,2010, which is the end point of our study.

A total of 1,204 British patients were followed up for the occurrence of a second cancer and death using the National Health Service Central Registers (Office of National Statistics 2006; Hawkins and Swerdlow 1992). They were followed up until the occurrence of a bone sarcoma, their death or December 31, 2006, whichever came first.

\section{Case-control sampling}

To make our results more comparable to those of published case-control studies, a nested case-control analysis was also performed within the cohort. Five controls were individually matched to second cancer sarcoma cases on sex, age, year of diagnosis, type of first cancer and duration 
of follow-up since the first cancer diagnosis. In this analysis, a case could potentially serve as a control for a case that had occurred earlier.

\section{Case identification}

A case was characterized by a patient having a tumor whose histology was defined as a bone sarcoma in the ICD (ICD codes 170.0-170.9). French bone sarcoma cases were identified from self-questionnaire, medical records and the National Registry of Causes of Death. English bone sarcoma cases were identified from the National Health Service Central Registers (Hawkins and Swerdlow 1992). Only bone sarcoma cases validated through a copy of the pathological record were considered as cases.

\section{Radiation dosimetry}

Retrospective dosimetric estimation was performed by reconstructing the body, i.e., developing a mathematical phantom of the individual patient from medical data files, at the time of treatment (Francois et al. 1988a, b) and the radiation therapy circumstances for each patient. Radiation doses were estimated at 188 points, fairly spatially allocated in the human body, from which 80 were located in bones. The Dos_EG software used was developed specifically for these dose calculations (Shamsaldin et al. 1998; Diallo et al. 1996; Francois et al. 1988a, b).

In the cohort analysis, the radiation dose was estimated in 59 bones for each of the 2,879 patients who had received radiotherapy during the follow-up period, i.e., up to 2 years before the end of their follow-up, because it is believed that the iatrogenic effects of radiotherapy do not appear within 2 years of treatment. If several points for which doses have been estimated were located within the same bone (some long bones, such as the femur, are long enough that two estimation points have been allocated within them), the mean dose was attributed to obtain a single dose by bone. In this case, the bone dose was more representative of the mean bone radiation dose than if the dose was estimated just based on one point into the bone. Obviously, if we could have estimated hundreds of doses in each bone, the accuracy of the average bone dose would have been much better, but unfortunately, we did not have these data. However, we do not expect it would affect the risk estimates significantly.

In the case-control study, only the local dose of radiation was considered, which means that for each case, the dose to the bone sarcoma site has been estimated, and for each matched control, the dose to the same site has also been estimated.

No dose estimation was performed for patients treated with brachytherapy because the focus was only on external

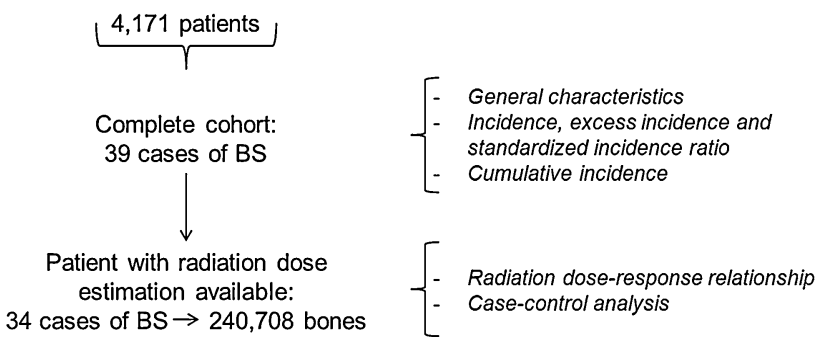

Fig. 1 Study population according to analyses; $B S$ bone sarcoma

radiotherapy here. Hence, five cases were excluded from the dose-response relationship estimation for this reason.

Bones

To take into account the wide heterogeneity of the radiation dose delivered throughout the body during radiation therapy, the radiation dose received at the bone level was considered here. The average human adult skeleton consists of 206 bones (Ramé and Thérond 2006). Bones of the arms, hands and feet (altogether 112 bones) were not considered because of the lack of precision concerning the position of the patient during the radiotherapy courses (two cases excluded, Fig. 1). Apart from these bones, there was missing information on several small bones of the face and mini-bones (a total of 23 bones). However, all the 71 remaining bones, i.e., the largest in terms of volume, had radiation dose estimated at least at one point and were thus all taken into account. The body of each patient was divided into 59 bones (ribs were grouped in pairs; Fig. 2).

\section{Chemotherapy quantification}

Drugs were grouped into seven classes according to their known mechanisms of action in the cell: vinca alkaloids, antimetabolites, alkylating agents, anthracyclines, cytotoxic antibiotics, epipodophyllotoxins and other drugs. The total cumulative amount of drugs administered for each class was expressed in moles per square meter, but also calculated in milligrams per square meter, as usual. Doses were expressed per square meter to take account of the body surface area that was used for dose administration.

Statistical methods

The SIRs of bone sarcoma were estimated as the ratio of observed to expected overall numbers of incident cases of bone sarcoma. The expected number of incident cases of bone sarcoma was defined as the number of person-years of follow-up in the given cell multiplied by the corresponding incidence rate of bone sarcoma from the British national cancer incidence rates (Office of National Statistics 2006). 


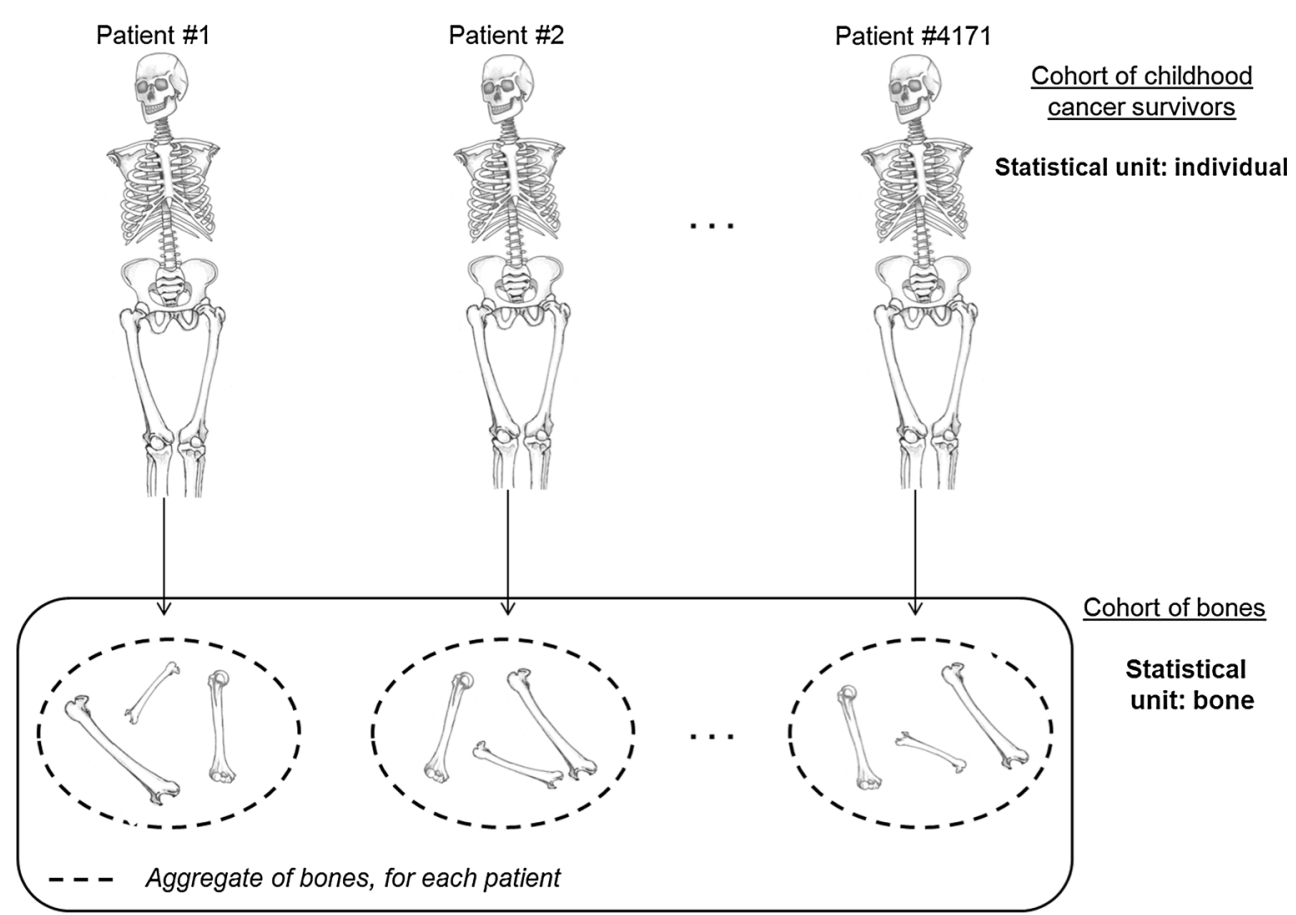

Fig. 2 Construction of the cohort of bones

British rates were used for patients both in France and in Britain because no reference incidence rate estimates of bone sarcoma were available in France. Inference for the SIR relied on exact calculations based on the Poisson distribution of the observed number of events (Belot et al. 2008). The absolute excess risk (AER) was estimated as the difference between the observed and expected number of incident bone sarcomas, divided by the number of personyears of follow-up.

Each bone of the same child could have received very different radiation doses during radiotherapy courses. We therefore performed analyses of the relationship between the radiation doses received and the risk of bone sarcoma using the bone as the statistical unit. In this analysis, each patient represented 59 bones, except for the 99 patients who had had a leg amputated, for whom only their remaining bones were taken into account. This method requires that every bone of each patient from the cohort is accounted for (if not amputated), in order to allow comparisons between the same bones of different patients.

As the dynamics of bone growth and radiation sensitivity were likely to be more similar among bones of the same structure and in the same area than between those in various areas of the body, six skeleton parts were defined within the human body in order to run a parsimonious stratified analysis: the head, the pectoral girdle, the ribs, the spine, the pelvis and the legs. Thanks to this type of analysis, bones were compared with other bones of the same area of the skeleton and this allowed us to take into account radiosensitivity heterogeneity in the whole body. In other words, this method did not allow for reducing radiation dose heterogeneity, but for better considering it and reducing variance of risk estimates.

An internal analysis was conducted using Cox's proportional hazard regression model for clustered data, in order to account for the lack of independence between the bones of the same patient, and with stratification on skeleton parts. The marginal approach of Wei et al. (1989), using robust "sandwich" variance estimates, was used. The Fine and Gray method with multiple imputations was used to take into account death as a competing risk (Pintilie 2011; Fine and Gray 1999; Ruan and Gray 2008; Resche-Rigon et al. 2006; Gooley et al. 1999). Therefore, the cumulative incidence and its variance were calculated based on the Marubini and Valsecchi formula (Marubini and Valsecchi 1995 , p. 341, equation 10.12). In these models, the timescale was attained age, and entry time was the age at diagnosis of the first cancer plus 2 years for French and 5 years for English patients (Thiebaut and Benichou 2004).

In order to evaluate the dose-response relationship between the bone radiation dose and the risk of bone sarcoma, the following models were fitted within Cox regression (Breslow and Day 1987):

1. Basic: hazard ratio $=1$

2. Linear: hazard ratio $=1+\beta_{1}$ dose 
Table 1 General characteristics of 4,171 survivors of childhood cancer

$C T$ chemotherapy, $R T$ radiotherapy, but no brachytherapy

${ }^{a}$ For irradiated patients only, except for those treated by brachytherapy. Not available for arms

\begin{tabular}{|c|c|c|}
\hline Country & France & Britain \\
\hline No. of patients (\%) & $2,967(71.1)$ & $1,204(28.9)$ \\
\hline $\begin{array}{l}\text { Years of treatment: } \\
\text { median (range) }\end{array}$ & $1977(1946-1985)$ & $1974(1942-1985)$ \\
\hline $\begin{array}{l}\text { Age at diagnosis in years: } \\
\text { median (range) }\end{array}$ & $4(0-20)$ & $5.0(0-15)$ \\
\hline $\begin{array}{l}\text { Follow-up in years: } \\
\text { median (range) }\end{array}$ & $26(5-61)$ & $28(5-62)$ \\
\hline $\begin{array}{l}\text { Sex: no. }(\%) \text { of males/no. } \\
(\%) \text { of females }\end{array}$ & $1,626(54.8) / 1,341(45.2)$ & $675(56.1) / 529(43.9)$ \\
\hline \multicolumn{3}{|c|}{ First cancer treatment no. $(\%)$} \\
\hline Neither CT nor RT & $212(7.1)$ & $196(16.3)$ \\
\hline CT but no RT & $681(23.0)$ & $203(16.9)$ \\
\hline RT but no CT & $578(19.5)$ & $363(30.1)$ \\
\hline $\mathrm{RT}$ and $\mathrm{CT}$ & $1,496(50.4)$ & $442(36.7)$ \\
\hline $\begin{array}{l}\text { Death before end of study } \\
\text { no. }(\%)\end{array}$ & $561(18.9)$ & $233(19.4)$ \\
\hline $\begin{array}{l}\text { Bone sarcomas during } \\
\text { follow-up no. }(\%)\end{array}$ & $35(1.2)$ & $4(0.3)$ \\
\hline \multicolumn{3}{|c|}{ Radiation dose $^{\mathrm{a}}$ (Gy): median (range) } \\
\hline Head & $0.5(0-110)$ & $0.5(0-126)$ \\
\hline Pectoral girdle & $0.7(0-180)$ & $0.6(0-90)$ \\
\hline Ribs & $1.0(0-99)$ & $0.6(0-90)$ \\
\hline Spine & $1.1(0-111)$ & $0.6(0-99)$ \\
\hline Pelvis & $0.8(0-47)$ & $0.3(0-61)$ \\
\hline Legs & $0.1(0-81)$ & $0.1(0-96)$ \\
\hline
\end{tabular}

3. Linear quadratic: hazard ratio $=1+\beta_{1}$ dose + $\beta_{2} \operatorname{dose}^{2}$

4. Linear exponential: hazard ratio $=\left(1+\beta_{1}\right.$ dose $) \times$ $\mathrm{e}^{\gamma \text { dose }}$

5. Linear quadratic exponential: hazard ratio $=\left(1+\beta_{1}\right.$ dose $\left.+\beta_{1} \operatorname{dose}^{2}\right) \times \mathrm{e}^{\gamma \text { dose }}$

with dose denoting the radiation dose to the bone.

Nested models were compared using the likelihood ratio test, and confidence intervals (CIs) for model parameters were estimated using profile likelihood (Moolgavkar and Venzon 1987). Only results derived from the selected model have been reported in this paper.

Due to the small number of incident bone sarcoma cases in each skeleton part (16 cases at most), a separate analysis for each set would have been underpowered. Consequently, only overall analyses of the whole skeleton, with stratification on the skeleton parts, were performed.

In the case-control analysis, conditional logistic regression was used. The adjustment variables were the same as in the cohort analysis, namely gender, age at diagnosis of the first cancer, type of first cancer, chemotherapy administration, number of drugs and spinal dose of radiation.

The EPICURE statistical software (Preston et al. 1993) and SAS $^{\circledR} 9.3$ (SAS Inst. Inc., Cary, NC) were used for the analyses. All tests were two-sided, and a $p$ value below 0.05 was considered significant. The proportional hazard assumption was verified in the final model.

\section{Results}

Cohort

The median follow-up of 4,171 patients was 26 years following the diagnosis of the first cancer (Table 1). From 5 to 37 years of age, 39 patients had developed bone sarcoma in 16 different bones. The majority of bone sarcomas developed in the legs (12) or head (11). Most of these cases had developed osteosarcoma (30); five had developed chondrosarcoma; and the four other cases had developed histiocytofibroma (2), Ewing's sarcoma and sarcoma without further precision. Of these cases, 27 were men and 12 women $(p=0.08)$. Among the 2,879 patients who had received radiotherapy during the follow-up period, 33 had developed bone sarcoma. The median absorbed dose of radiation to the bones was $0.48 \mathrm{~Gy}$ (range 0.00-179.83 Gy).

The cumulative incidences of bone sarcoma at 10, 20 and 35 years of age were, respectively, $0.3 \%$ (95\% CI 
Table 2 Incidence of bone sarcoma, excess incidence and standardized incidence ratio

\begin{tabular}{|c|c|c|c|c|c|c|}
\hline & \multirow{2}{*}{$\begin{array}{l}\text { Patients still } \\
\text { followed up }\end{array}$} & \multicolumn{5}{|c|}{ Bone sarcoma } \\
\hline & & $\begin{array}{l}\text { \# Observed } \\
\text { cases }\end{array}$ & $\begin{array}{l}\text { \# Expected } \\
\text { cases }^{\mathrm{a}}\end{array}$ & $\begin{array}{l}\text { Annual incidence } \\
\text { per } 10^{5} \text { person-years }\end{array}$ & AER per $10^{5}$ person-years ${ }^{\mathrm{b}}$ & $\operatorname{SIR}^{\mathrm{c}}$ \\
\hline Total & 4,171 & 39 & 0.87 & $35.9(24.8-47.9)$ & $35.1(24.0-47.1)$ & $44.8(31.0-59.8)$ \\
\hline \multicolumn{7}{|c|}{ Years after diagnosis } \\
\hline $5-9$ & 4,171 & 14 & 0.27 & $42.8(21.4-67.2)$ & $41.9(20.6-66.4)$ & $51.9(25.9-81.5)$ \\
\hline $10-19$ & 3,867 & 21 & 0.37 & $56.8(35.2-81.1)$ & $55.8(34.1-80.1)$ & $56.8(35.1-81.1)$ \\
\hline $20-29$ & 3,388 & 3 & 0.15 & $11.7(0.0-27.4)$ & $11.1(0.0-26.8)$ & $20.0(0.0-46.7)$ \\
\hline$\geq 30$ & 1,575 & 1 & 0.07 & $7.5(0.0-22.4)$ & $6.9(-0.5$ to 21.9$)$ & $14.3(0.0-42.9)$ \\
\hline \multicolumn{7}{|c|}{ Attained age (years) } \\
\hline $5-9$ & 4,171 & 4 & 0.06 & $28.7(7.2-57.5)$ & $28.3(6.8-57.1)$ & $66.7(16.7-133.3)$ \\
\hline $10-19$ & 4,088 & 27 & 0.45 & $85.2(53.6-119.9)$ & $83.8(52.2-118.5)$ & $60.0(37.8-84.4)$ \\
\hline $20-29$ & 3,643 & 4 & 0.22 & $12.2(3.1-24.4)$ & $11.5(2.4-23.7)$ & $18.2(4.5-38.4)$ \\
\hline$\geq 30$ & 2,521 & 4 & 0.14 & $14.7(3.7-29.3)$ & $14.1(3.2-28.8)$ & $28.6(7.1-57.1)$ \\
\hline \multicolumn{7}{|c|}{ Age at diagnosis (years) } \\
\hline $0-4$ & 2,184 & 22 & 0.47 & $37.7(22.3-54.9)$ & $36.9(21.5-54.1)$ & $46.8(27.7-68.1)$ \\
\hline $5-9$ & 1,041 & 11 & 0.22 & $41.1(18.7-67.2)$ & $40.3(17.9-66.4)$ & $50.0(22.7-81.8)$ \\
\hline$\geq 10$ & 946 & 6 & 0.18 & $25.4(8.5-46.6)$ & $24.7(7.7-45.8)$ & $33.3(11.1-61.1)$ \\
\hline \multicolumn{7}{|c|}{ Type of treatment } \\
\hline Surgery alone & 408 & 1 & 0.09 & $8.0(0.0-23.9)$ & $7.3(-0.7$ to 23.3$)$ & $11.1(0.0-33.3)$ \\
\hline CT but no RT & 884 & 5 & 0.17 & $25.2(5.0-50.4)$ & $24.4(4.2-49.6)$ & $29.4(5.9-58.8)$ \\
\hline RT but no CT & 941 & 5 & 0.21 & $17.3(3.5-34.7)$ & $16.6(2.7-33.9)$ & $23.8(4.8-47.6)$ \\
\hline $\mathrm{RT}$ and $\mathrm{CT}$ & 1,938 & 28 & 0.39 & $59.0(37.9-82.2)$ & $58.2(37.1-81.3)$ & $71.8(46.2-100.0)$ \\
\hline
\end{tabular}

$C T$ chemotherapy, $R T$ radiotherapy, but no brachytherapy

${ }^{a}$ From the United Kingdom general population rates

b $A E R$ absolute excess risk, defined as [(observed - expected)/person-years]

c $S I R$ standardized incidence ratio, defined as (observed/expected)

$0.1-0.4 \%), 0.9 \%$ (95\% CI $0.6-1.2 \%)$ and $1.1 \%(95 \%$ CI $0.8-1.5 \%)$. The overall incidence was about 45 -fold higher than expected in the general population $(95 \% \mathrm{CI}$ 31.0-59.8) (Table 2).

The SIR stabilized then decreased with increasing attained age (Table 2), except that the SIR was higher after 30 years than between 20 and 29 years. No trend was found concerning the SIR with time since first cancer diagnosis. Also, no trend of the AER was observed with time since first cancer diagnosis, nor with increasing attained age. Both the SIR and AER were higher following radiotherapy plus chemotherapy than they were following either of these modalities alone.

In the univariate analysis, type of first cancer and risk of bone sarcoma as a secondary cancer were closely linked (Table 3, $p<0.001$ ). Patients who had retinoblastoma, Ewing's, soft tissue sarcomas and Hodgkin's disease had a significantly higher risk of bone sarcoma than patients who had a nephroblastoma as the first cancer.

Bone sarcomas were more likely to occur in the pelvis $(\mathrm{HR}=49.2,95 \%$ CI 15.0-161.2), legs $(\mathrm{HR}=11.0,95 \%$ CI 3.9-31.1) and head (HR $=11.3,95 \%$ CI 3.9-32.4) than in the trunk. After adjustment on the radiation dose, hazard ratios were higher: 93.7 (95\% CI 27.2-327.6), 67.5 (95\% CI 18.3-249.1) and 12.9 (95\% CI 4.4-37.4) for pelvis, legs and head, respectively.

Risk model for radiations

Upon modeling the association between the hazard rate of bone sarcoma and bone doses, a linear model fitted the data the most adequately (Fig. 3). The excess relative risk (ERR) per Gy in this model was 1.78 (95\% CI 0.62-5.94). This entailed the same hazard per additional Gray at low (less than $1 \mathrm{~Gy}$ ) as at high (more than $10 \mathrm{~Gy}$ ) doses. Compared with patients who did not receive radiation therapy, the risk of bone sarcoma for those who received more than 30 Gy was almost 120-fold higher (Table 4; Fig. 3).

\section{Chemotherapy}

Chemotherapy administration was a nonsignificant risk factor for bone sarcoma $(\mathrm{HR}=1.9,95 \%$ CI 0.6-5.9) after 
Table 3 Risk of bone sarcoma according to the type of first cancer

\begin{tabular}{|c|c|c|c|c|c|c|}
\hline & $\begin{array}{l}\text { No. of cases/ } \\
\text { no. of patients }\end{array}$ & $\begin{array}{l}\text { Radiation } \\
\text { therapy }(\%)\end{array}$ & $\begin{array}{l}\text { Average bone dose (Gy), } \\
\text { mean, median }(\text { range })^{\mathrm{a}}\end{array}$ & $\begin{array}{l}\text { AER per } 10^{5} \text { PYR } \\
(95 \% \mathrm{CI})\end{array}$ & $\operatorname{SIR}^{\mathrm{b}}(95 \% \mathrm{CI})$ & $\begin{array}{l}\text { Unadjusted HR } \\
(95 \% \mathrm{CI})\end{array}$ \\
\hline Nephroblastoma & $2 / 851$ & 72.7 & $6.6,5.7(0.1-24.5)$ & $7.6(-0.8$ to 20.3$)$ & $10.5(0.0-26.3)$ & $1(\operatorname{Ref})$ \\
\hline Neuroblastoma & $2 / 573$ & 55.2 & $5.1,4.0(0.1-29.1)$ & $12.6(-0.8$ to 32.7$)$ & $16.7(0.0-41.7)$ & $1.6(0.2-11.5)$ \\
\hline $\begin{array}{l}\text { Hodgkin's } \\
\text { disease }\end{array}$ & $5 / 378$ & 91.3 & $13.0,12.6(0.0-40.0)$ & $51.2(9.6-103.2)$ & $62.5(12.5-125.0)$ & $6.2(1.2-31.5)$ \\
\hline $\begin{array}{l}\text { Non-Hodgkin } \\
\text { lymphoma }\end{array}$ & $3 / 459$ & 59.5 & $5.8,4.8(0.1-25.0)$ & $27.1(-0.8$ to 64.3$)$ & $33.3(0.0-77.8)$ & $3.1(0.5-18.4)$ \\
\hline $\begin{array}{c}\text { Soft tissue } \\
\text { sarcoma }\end{array}$ & $11 / 535$ & 62.6 & $3.2,1.9(0.0-17.4)$ & $76.6(34.4-125.8)$ & $100.0(45.5-163.6)$ & $9.3(2.0-41.8)$ \\
\hline $\begin{array}{l}\text { Ewing's } \\
\text { sarcoma }\end{array}$ & $6 / 141$ & 92.2 & $3.8,2.7(0.0-16.8)$ & $179.5(59.2-329.7)$ & $200.0(66.7-366.7)$ & $20.1(4.1-98.8)$ \\
\hline CNS tumor & $1 / 690$ & 83.0 & $8.0,3.7(0.3-35.0)$ & $4.6(-0.7$ to 15.3$)$ & $7.1(0.0-21.4)$ & $0.6(0.1-6.9)$ \\
\hline Gonadal tumor & $1 / 227$ & 38.3 & $7.9,7.6(0.5-28.8)$ & $16.7(-0.7$ to 51.5$)$ & $25.0(0.0-75.0)$ & $2.1(0.2-22.7)$ \\
\hline Retinoblastoma & $7 / 144$ & 81.3 & $1.8,1.2(0.1-26.3)$ & $220.4(62.3-410.0)$ & $233.3(66.7-433.3)$ & $25.0(5.2-120.9)$ \\
\hline $\begin{array}{l}\text { Other first } \\
\text { cancers }\end{array}$ & $1 / 173$ & 48.6 & $7.5,6.4(0.2-28.7)$ & $21.5(-0.7$ to 65.9$)$ & $33.3(0.0-100.0)$ & $2.7(0.2-29.4)$ \\
\hline Entire cohort & $39 / 4,171$ & 69.0 & $6.8,4.7(0.0-40.0)$ & $35.1(24.0-47.1$ & $44.8(31.0-59.8)$ & - \\
\hline
\end{tabular}

PYR person-years, $C I$ confidence interval, $H R$ hazard ratio in a Cox's proportional hazards model with clustering in order to take into account the fact that several bones are from the same patients

${ }^{a}$ In patients with radiotherapy, except for those treated by brachytherapy

b As compared to the general British population: AER absolute excess risk, defined as [(obs - exp)/person-years], SIR standardized incidence ratio, defined as (obs/exp)

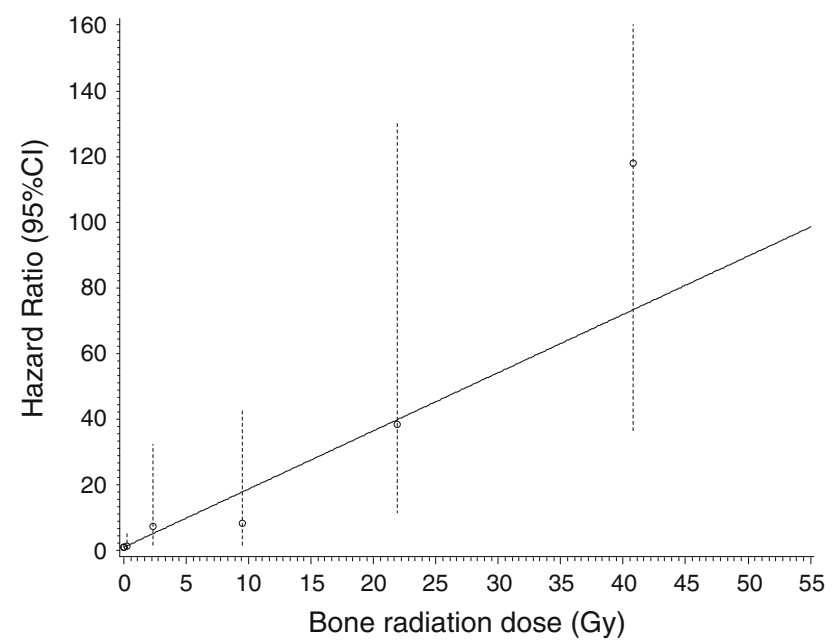

Fig. 3 Hazard ratio for bone sarcoma according to the radiation dose to the bone; the circles represent observed values by radiation dose, and vertical bars represent corresponding $95 \% \mathrm{CI}$. The curve is the prediction using the following model: HR $=1+1.773 *$ dose; $95 \%$ CI for 1.773: 0.6213-5.935; six levels of dose represented are no radiation dose, $0-1,1-5,5-15,15-30$ Gy and more than 30 Gy. Note The upper-bound confidence limit of the last category of dose has been truncated for better readability

adjustment. We failed to evidence a significant role for a given drug category, even alkylating agents.

No interaction was found between the dose of ionizing radiation and chemotherapy in the cohort $(p=0.20)$ or case-control analysis $(p=0.43)$.
Evaluation of the approach

Odds ratios estimated from the nested case-control study were higher than hazard ratio estimates from the cohort analysis, with CI very much larger in the casecontrol study due to the small number of cases (Table 4). However, CI overlaps, hence there were no statistical differences between the two approaches, but that did not mean that they are similar. Nevertheless, we strongly suppose that the nonsignificance is a consequence of the lack of power due to the low number of cases and that the cohort analysis was more accurate.

\section{Discussion}

Despite the relatively large size of the cohort and the long duration of follow-up, the main limitation of our study is the small number of bone sarcomas: 39 cases, of whom only 34 had available radiation doses.

Also, we were unable to take into account all the bones of the body and the total radiation dose received by each bone and its distribution. For example, for long bones such as the femur, the radiation dose estimation was performed only on two physical sites. Nonetheless, the radiation dose was estimated in at least one site for the majority of bones. 
Table 4 Bone sarcoma's risk according to the bone radiation dose

\begin{tabular}{|c|c|c|c|c|c|c|}
\hline & $\begin{array}{l}\text { No } \\
\text { radiation }\end{array}$ & 0-1 Gy & $1-5 \mathrm{~Gy}$ & $5-15$ Gy & 15-30 Gy & 30 Gy or more \\
\hline Bone sarcomas/exposed bones & $4 / 80,643$ & $5 / 90,574$ & $3 / 22,306$ & $2 / 16,467$ & $7 / 17,060$ & $13 / 13,658$ \\
\hline $\begin{array}{l}\text { Median bone radiation } \operatorname{dose}^{\mathrm{a}} \\
\text { (range) }\end{array}$ & 0 & $0.2(0.0-1.0)$ & $2.0(1.0-5.0)$ & $9.2(5.0-15.0)$ & $21.5(15.0-30.0)$ & $38.1(30.0-179.8)$ \\
\hline $\mathrm{HR}^{\mathrm{b}}(95 \% \mathrm{CI})$ & 1 (Ref) & $1.4(0.3-5.7)$ & $7.3(1.6-32.3)$ & $8.2(1.6-42.9)$ & $38.4(11.3-130.5)$ & $117.9(36.5-380.6)$ \\
\hline $\begin{array}{l}\text { Median local bone radiation } \\
\text { dose }^{\mathrm{a}} \text { (range) }\end{array}$ & 0 & $0.2(0.0-0.7)$ & $2.4(1.1-4.7)$ & $8.9(5.2-13.9)$ & $21.8(16.5-28.2)$ & $42.9(30.7-73.1)$ \\
\hline $\mathrm{OR}^{\mathrm{c}}(95 \% \mathrm{CI})$ & 1 (Ref) & $2.0(0.4-9.5)$ & $34.7(2.2-535.5)$ & $22.2(1.5-324.0)$ & $415.5(20.1-8,595.5)$ & $898.0(27.5-29,325.7)$ \\
\hline
\end{tabular}

${ }^{a}$ Dose in Gray (Gy)

${ }^{\mathrm{b}} H R$ hazard ratio in a Cox's proportional hazards model with clustering in order to take into account the fact that several bones are from the same patients, adjustment for age at diagnosis, sex, type of first cancer, chemotherapy and spinal radiation dose, and stratification on the skeleton parts

${ }^{c} O R$ odds ratio in a conditional logistic regression in a nested case-control analysis (34 cases/170 controls, matched on sex, age and year of diagnosis and type of the first cancer), adjustment on chemotherapy and spinal radiation dose

Several factors add credence to the results presented. For example, previous medical and treatment data were collected exhaustively. The response rate in French patients who were alive when the questionnaire was sent was $75 \%$, higher than in the Childhood Cancer Survivor Study (Robison et al. 2002), and the nonresponders among these patients were nevertheless followed up for 17 years on average, whereas British patients were followed up from a National Cancer Registry. Among cases that were only registered as cause of death, only the validated ones were considered as cases in the analyses. Hence, all cases in our analyses had been confirmed by histopathologists.

In our cohort, the ERR per Gy was 1.78 (95\% CI $0.62-5.94)$, i.e., the hazard ratio for a dose of $1 \mathrm{~Gy}$ was 2.8 (95 \% CI 1.6-6.9). This value is lower but compatible with that expected from the last report on the analysis of Hiroshima and Nagasaki survivors in which a threshold dose of 0.85 Gy was observed, with each Gray above this dose multiplying the risk of bone sarcoma by 7.5 (95\% CI 1.3-23.1) (Samartzis et al. 2011). Our results are also compatible with those of Tucker et al. (1987), Hawkins et al. (1996) and Henderson et al. (2012), although all of them only considered the local radiation dose. Indeed, Tucker pointed out an increased risk with an increased radiation dose, with a relative risk of about 40 for doses above 60 Gy relative to no radiation. Hawkins et al. estimated a relative risk of 93.4 (95\% CI 6.8-1,285.4) for doses between 30 and $50 \mathrm{~Gy}$, which is close to our estimate of $117.9(36-5,380.6)$ for doses greater than $30 \mathrm{~Gy}$. The same conclusions could be drawn from Henderson's paper, which exhibits an excess odds ratio per Gray (EOR/ Gy) of 1.32 (95\% CI 0.44-4.22) and an OR of 114.1 (95\% CI 13.5-964.8) for doses higher than $50 \mathrm{~Gy}$. However, contrary to the findings of Hawkins et al., no decline in the risk of bone sarcoma was observed for very high doses (more than $15 \mathrm{~Gy}$ ). These three papers also noted an increase in the risk of bone sarcoma if patients had been treated with chemotherapy, which is consistent with our results, although we did not identify a drug class specifically associated with this increase, even when considering alkylating agents. The cell-killing effect is known to decrease the radiation dose-related risk at high doses, because at a given level of dosage all cells die, even the cancerous ones, and thus, no secondary cancer could be seen in the organ. However, other issues could be observed, like the death of the organ. In our analysis, no cell-killing effect was demonstrated, such as that seen in other smaller organs such as the thyroid (Sigurdson et al. 2005).

Another childhood cancer survivors' cohort, which did not include radiation dose reconstruction, estimated an SIR of 28.1 (95\% CI 9.1-65.7) and an AER of 28 per 100,000 person-years-values in accordance with our results (Cardous-Ubbink et al. 2007).

We estimated a higher increase in the risk of bone sarcoma following high radiation doses than that found in studies of retinoblastoma survivors (Kleinerman et al. 2005; Wong et al. 1997). This suggests that genetic retinoblastoma survivors, who have a much higher baseline risk than other cancer survivors due to a common genetic mechanism between retinoblastoma and sarcoma (Friend et al. 1986), do not exhibit greater sensitivity to radiation. A sensitivity analysis has been run excluding all retinoblastoma patients (results not shown); results were similar, so we kept them in our study to improve statistical power.

The new approach proposed in this article allows the evaluation of the radiation dose-response relationship in a cohort analysis, which exhibits a much greater precision than the usual case-control approach and allows for taking into account the radiation dose heterogeneity in the body. It should also avoid selection biases that may be found in case-control analyses. 


\section{Conclusion}

Based on a cohort of 4,171 survivors of childhood cancer with a median follow-up of 26 years and 39 incidents of second bone sarcomas, this study showed that the increase in the risk of bone sarcoma is well described by a linear function of the radiation dose received by the bones. Consequently, the risk of bone sarcoma is mainly a serious concern at high radiation doses. Also, it seems that almost all the risk of bone sarcoma is concentrated in the 30 years following childhood cancer treatment. However, it may be too early, based on the relatively short follow-up, to reach a conclusion on this aspect. Lastly, it appears that retinoblastoma, Ewing's, soft tissue sarcomas and Hodgkin's disease are primary cancer types with the highest risks of subsequent neoplasm. To conclude, it is crucial to lower the radiation dose to the bones because the risk of sarcoma increases continuously with increasing radiation dose to bones, without plateau. As much as is possible, other therapeutic solutions should be preferred to radiotherapy in bone sarcoma-sensitive areas, such as the head or pelvis. Also, intervention strategies such as screening or prevention of SMNs should be based on first cancer types with the highest risks of subsequent neoplasm.

Acknowledgments The authors are grateful to Ms. Martine Labbé and Ms. Catherine Paoletti for their help in data management, and all the physicians and physicists who participated in the planning of the study or data collection at the Gustave Roussy Institute (Villejuif), Thames Cancer Registry (London), Institut Godinot (Reims), Institut Curie (Paris), Centre Regaud (Toulouse) and Centre Lacassagne (Nice). This study was supported by the Ligue Nationale Contre le Cancer (LNCC), Institut de Recherche en Santé Publique (IRESP), Programme Hospitalier de Recherche Clinique (PHRC), Agence Française de Sécurité Sanitaire et Produits de Santé (AFFSAPS), the Pfizer Foundation for Childhood and Adolescent Health, and the European Commission, FP7-Health, PanCareSurFup project (Grant Agreement Number 257505). Boris Schwartz is grateful to the LNCC for a doctoral grant. The authors also thank Lorna Saint Ange for editing and Pauline Le Paih for drawing.

Open Access This article is distributed under the terms of the Creative Commons Attribution License which permits any use, distribution, and reproduction in any medium, provided the original author(s) and the source are credited.

\section{References}

Bassal M, Mertens AC, Taylor L, Neglia JP, Greffe BS, Hammond S, Ronckers CM, Friedman DL, Stovall M, Yasui YY, Robison LL, Meadows AT, Kadan-Lottick NS (2006) Risk of selected subsequent carcinomas in survivors of childhood cancer: a report from the Childhood Cancer Survivor Study. J Clin Oncol 24(3):476-483

Belot A, Grosclaude P, Bossard N, Jougla E, Benhamou E, Delafosse P, Guizard AV, Molinié F, Danzon A, Bara S, Bouvier AM, Trétarre B, Binder-Foucard F, Colonna M, Daubisse L, Hédelin G, Launoy G, Le Stang N, Maynadié M, Monnereau A,
Troussard X, Faivre J, Collignon A, Janoray I, Arveux P, Buemi A, Raverdy N, Schvartz C, Bovet M, Chérié-Challine L, Estève J, Remontet L, Velten M (2008) Cancer incidence and mortality in France over the period 1980-2005. Rev Epidemiol Sante Publique 56(3):159-175

Berrington de Gonzalez A, Kutsenko A, Rajaraman P (2012) Sarcoma risk after radiation exposure. Clin Sarcoma Res 2(1):18

Breslow NE, Day NE (1987) Statistical methods in cancer research. IARC workshop 25-27 May 1983. IARC Science Publication 82:1-406

Cardous-Ubbink MC, Heinen RC, Bakker PJ, Bakker PJ, van den Berg H, Oldenburger F, Caron HN, Voûte PA, van Leeuwen FE (2007) Risk of second malignancies in long-term survivors of childhood cancer. Eur J Cancer 43(2):351-362

Diallo I, Lamon A, Shamsaldin A, Grimaud E, de Vathaire F, Chavaudra J (1996) Estimation of the radiation dose delivered to any point outside the target volume per patient treated with external beam radiotherapy. Radiother Oncol 38(3):269-271

Fine PF, Gray RJ (1999) A proportional hazards model for the subdistribution of a competing risk. JASA 94:496-509

Francois P, Beurtheret C, Dutreix A (1988a) Calculation of the dose delivered to organs outside the radiation beams. Med Phys 15(6):879-883

Francois P, Beurtheret C, Dutreix A, De Vathaire F (1988b) A mathematical child phantom for the calculation of dose to the organs at risk. Med Phys 15(3):328-333

Friedman DL, Whitton J, Leisenring W, Mertens AC, Hammond S, Stovall M, Donaldson SS, Meadows AT, Robison LL, Neglia JP (2010) Subsequent neoplasms in 5-year survivors of childhood cancer: the Childhood Cancer Survivor Study. J Natl Cancer Inst 102(14):1083-1095

Friend SH, Bernards R, Rogelj S, Weinberg RA, Rapaport JM, Albert DM, Dryja TP (1986) A human DNA segment with properties of the gene that predisposes to retinoblastoma and osteosarcoma. Nature 323(6089):643-646

Gooley TA, Leisenring W, Crowley J, Storer BE (1999) Estimation of failure probabilities in the presence of competing risks: new representations of old estimators. Stat Med 18(6):695-706

Hawkins MM, Lancashire ER, Winter DL, Frobisher C, Reulen RC, Taylor AJ, Stevens MC, Jenney M (2008) The British Childhood Cancer Survivor Study: objectives, methods, population structure, response rates and initial descriptive information. Pediatr Blood Cancer 50(5):1018-1025

Hawkins MM, Swerdlow AJ (1992) Completeness of cancer and death follow-up obtained through the National Health Service Central Register for England and Wales. $\mathrm{Br} \mathrm{J}$ Cancer 66(2):408-413

Hawkins MM, Wilson LM, Burton HS, Potok MH, Winter DL, Marsden HB, Stovall MA (1996) Radiotherapy, alkylating agents, and risk of bone cancer after childhood cancer. J Natl Cancer Inst 88(5):270-278

Henderson TO, Rajaraman P, Stovall M, Constine LS, Olive A, Smith SA, Mertens A, Meadows A, Neglia JP, Hammond S, Whitton J, Inskip PD, Robison LL, Diller L (2012) Risks factors associated with secondary sarcomas in childhood cancer survivors: a report from the Childhood Cancer Survivor Study. Int J Radiat Oncol Biol Phys 84:224-230

Kleinerman RA, Tucker MA, Tarone RE, Abramson DH, Seddon JM, Stovall M, Li FP, Fraumeni JF Jr (2005) Risk of new cancers after radiotherapy in long-term survivors of retinoblastoma: an extended follow-up. J Clin Oncol 23(10):2272-2279

Le Vu B, de Vathaire F, Shamsaldin A, Hawkins MM, Grimaud E, Hardiman C, Diallo I, Vassal G, Bessa E, Campbell S, Panis X, Daly-Schveitzer N, Lagrange JL, Zucker JM, Eschwège F, Chavaudra J, Lemerle J (1998) Radiation dose, chemotherapy and risk of osteosarcoma after solid tumours during childhood. Int J Cancer 77(3):370-377 
Marubini E, Valsecchi MG (1995) Analysing survival data from clinical trials and observational studies. Wiley, Hoboken, NJ

Moolgavkar SH, Venzon DJ (1987) A method for computing profile likelihood based confidence bounds. Ann Stat 15:346-359

Office of National Statistics (2006) Cancer statistics registrationsseries MB1. The Stationery Office, London

Olsen JH, Moller T, Anderson H, Langmark F, Sankila R, Tryggvadóttír L, Winther JF, Rechnitzer C, Jonmundsson G, Christensen J, Garwicz S (2009) Lifelong cancer incidence in 47,697 patients treated for childhood cancer in the Nordic countries. J Natl Cancer Inst 101(11):806-813

Pintilie M (2011) An introduction to competing risks analysis. Rev Esp Cardiol 64(7):599-605

Preston DL, Lubin JH, Pierce DA (1993) EPICURE user's guide. Hirosoft International Corporation, Seattle

Ramé A, Thérond S (2006) Anatomie et physiologie. Elsevier Masson, Issy les Moulineaux, p 318

Resche-Rigon M, Azoulay E, Chevret S (2006) Evaluating mortality in intensive care units: contribution of competing risks analyses. Crit Care 10(1):R5

Reulen RC, Frobisher C, Winter DL, Kelly J, Lancashire ER, Stiller CA, Pritchard-Jones K, Jenkinson HC, Hawkins MM (2011) British Childhood Cancer Survivor Study Steering Group. Longterm risks of subsequent primary neoplasms among survivors of childhood cancer. JAMA 305(22):2311-2319

Robison LL, Mertens AC, Boice JD, Breslow NE, Donaldson SS, Green DM, Li FP, Meadows AT, Mulvihill JJ, Neglia JP, Nesbit ME, Packer RJ, Potter JD, Sklar CA, Smith MA, Stovall M, Strong LC, Yasui Y, Zeltzer LK (2002) Study design and cohort characteristics of the Childhood Cancer Survivor Study: a multi-institutional collaborative project. Med Pediatr Oncol 38(4):229-239
Ruan PK, Gray RJ (2008) Analyses of cumulative incidence functions via non-parametric multiple imputation. Stat Med 27(27):5709-5724

Samartzis D, Nishi N, Hayashi M, Cologne J, Cullings HM, Kodama K, Miles EF, Funamoto S, Suyama A, Soda M, Kasagi F (2011) Exposure to ionizing radiation and development of bone sarcoma: new insights based on atomic-bomb survivors of Hiroshima and Nagasaki. J Bone Joint Surg Am 93(11):1008-1015

Shamsaldin A, Grimaud E, Hardiman C, Diallo I, de-Vathaire F, Chavaudra J (1998) Dose distribution throughout the body from radiotherapy for Hodgkin's disease in childhood. Radiother Oncol 49(1):85-90

Sigurdson AJ, Ronckers CM, Mertens AC, Stovall M, Smith SA, Liu Y, Berkow RL, Hammond S, Neglia JP, Meadows AT, Sklar CA, Robison LL, Inskip PD (2005) Primary thyroid cancer after a first tumour in childhood (the Childhood Cancer Survivor Study): a nested case-control study. Lancet 365(9476):2014-2023

Thiebaut AC, Benichou J (2004) Choice of time-scale in Cox's model analysis of epidemiologic cohort data: a simulation study. Stat Med 23(24):3803-3820

Tucker MA, D’Angio GJ, Boice JD, Strong LC, Li FP, Stovall M, Stone BJ, Green DM, Lombardi F, Newton W (1987) Bone sarcomas linked to radiotherapy and chemotherapy in children. N Engl J Med 317(10):588-593

Wei LJ, Lin DY, Weissfeld L (1989) Regression analysis of multivariate incomplete failure time data by using the marginal distributions. JASA 84:1065-1073

Wong FL, Boice JD Jr, Abramson DH, Tarone RE, Kleinerman RA, Stovall M, Goldman MB, Seddon JM, Tarbell N, Fraumeni JF Jr, Li FP (1997) Cancer incidence after retinoblastoma. Radiation dose and sarcoma risk. JAMA 278(15):1262-1267 